\title{
O QUE DISTINGUE A ECONOMIA DO CONHECIMENTO? IMPLICAÇÕES PARA A EDUCAÇÃO
}

\author{
DAVID GUILE \\ Escola de Educação ao Longo da Vida e Desenvolvimento Internacional \\ Instituto de Educação da Universidade de Londres \\ dguile@ioe.ac.uk \\ Tradução: Inês Teixeira Barrancos \\ Revisão: Iracema Dulley \\ Coordenação: Vera Luiza Visockis Macedo
}

\begin{abstract}
RESUMO
O objetivo deste artigo é compensar a insuficiência da teorização a respeito da economia do conhecimento por parte dos sociólogos e identificar as implicações da análise aqui desenvolvida para a educação. O texto começa distinguindo e expondo as diferentes explicações do papel do conhecimento na economia do conhecimento; em seguida, argumenta sobre as conexões que podem ser estabelecidas entre essas duas concepções de conhecimento e a economia do conhecimento por meio do conceito de "culturas epistêmicas" (Cetina, 1999), e conclui examinando as implicações das "culturas epistêmicas" para a educação.

FORMAÇÃO PROFISSIONAL - POLITICAS EDUCACIONAIS - SOCIEDADE DO CONHECIMENTO
\end{abstract}

\section{ABSTRACT}

WHAT IS DISTINCTIVE ABOUT THE KNOWLEDGE ECONOMY? IMPLICATIONS FOR EDUCATION. The aim of this article is to redress the under theorisation of the knowledge economy by sociologists and to identify the implications of the analysis developed here for education. The chapter starts by distinguishing between and accounting for the different explanations of the role of knowledge in the knowledge economy, it then argues that connections can be made between these two conceptions of knowledge and the knowledge economy though the concept of epistemic cultures (Cetina, 1999). It then concludes by considering the implications of epistemic cultures for education.

PROFESSIONAL TRAINING - EDUCATIONAL POLICIES - KNOWLEDGE SOCIETY 
A idéia de que vivemos e trabalhamos em uma sociedade/economia do conhecimento ganhou destaque cada vez maior nas políticas educacionais e econômicas do Reino Unido e da União Européia na última década. Para o senso comum, o conhecimento constitui atualmente o fator de produção mais importante na economia das sociedades industriais avançadas; e o corolário resultante é que as populações desses países exigem maior acesso ao conhecimento, representado pelas qualificações pessoais.

Contudo, a natureza da economia do conhecimento foi pouco teorizada tanto em termos sociológicos quanto em termos filosóficos. Sociólogos importantes como Bell (1974) e Castells (1996) definiram a economia do conhecimento, em termos de conhecimento, como principal fator da produção e a tecnologia como seu principal recurso. Contudo, a natureza desse conhecimento tem sido questionada por outros cientistas sociais como, por exemplo, Gibbons et al. (1994) e Nonaka e Takeuchi (1 995), que oferecem explicações muito diferentes a respeito da natureza distintiva do conhecimento na economia do conhecimento. Isso leva não só à incoerência teórica, mas também a políticas e práticas educacionais que são muitas vezes contraditórias. Outro problema com relação a essas explicações da economia do conhecimento é que Bell e Castells não consideram a natureza mutável das relações sociais nas quais a tecnologia está inserida, ao passo que Gibbons et al. e Nonaka e Takeuchi nem mesmo discutem a questão da tecnologia. Contudo, mudanças aceleradas vêm ocorrendo desde o início da revolução industrial. Desse modo, permanece a questão a respeito do que distingue essa fase aparentemente nova no desenvolvimento das sociedades capitalistas.

O texto visa compensar a insuficiente teorização sobre a economia do conhecimento feita pelos sociólogos e identificar as suas implicações na análise da educação. Distingue as explicações sobre o papel do conhecimento na economia do conhecimento; argumenta acerca das conexões que podem ser estabelecidas entre essas concepções e a economia do conhecimento por meio do conceito de "culturas epistêmicas" (Cetina, 1999), e conclui examinando as implicações das "culturas epistêmicas" para a educação. 


\section{CONHECIMENTO TEÓRICO COMO CONDIÇÃO SINE QUA NON DA ECONOMIA DO CONHECIMENTO}

O consenso difundido entre os cientistas sociais desde meados da década de 1950 é de que mudanças econômicas e tecnológicas características da época vêm ocorrendo em economias industriais avançadas. Uma corrente específica do determinismo tecnológico que tem tido muito influência sobre a teoria social é a tese da "economia do conhecimento" (Osborne, 1998). O conceito de economia do conhecimento foi cunhado por Drucker (1969) para se referir à aplicação do conhecimento de qualquer campo ou fonte, novo ou velho, como estímulo ao desenvolvimento econômico. Contudo, a figura mais conhecida por chamar atenção para o impacto do conhecimento nas economias das sociedades industriais avançadas é Daniel Bell.

Bell (1974) acreditava que alguma forma de conhecimento sempre foi fundamental para o funcionamento de qualquer sociedade, no sentido de que o conhecimento é um universal antropológico. Bell argumentava que o traço distintivo das sociedades industriais avançadas era que o conhecimento teórico - "proposições organizadas de fatos ou idéias, apresentando um juízo ponderado ou resultado experimental" - teria passado a constituir o "princípio axial" do desenvolvimento ( 1974 , p. I 75). O conhecimento teórico teria adquirido esse novo papel porque a mudança de uma economia de produção para uma economia de serviços significava que: "quando o conhecimento se torna envolvido de alguma forma sistemática na transformação aplicada dos recursos, então pode-se dizer que o conhecimento, não o trabalho, é a fonte de valor" (Bell, 1979, p. 169).

Assim, o caráter e a riqueza das sociedades industriais avançadas passam a ser determinados por uma "teoria do valor do conhecimento", uma vez que o conhecimento teórico servia a dois propósitos principais: sua aplicação por meio do processo de Pesquisa e Desenvolvimento - P\&D - consistia na principal fonte de inovação e ele era essencial para a formulação de políticas de auxílio ao planejamento. Além disso, esse novo papel do conhecimento teórico exigia, de acordo com Bell ( 1974, p.29), uma "tecnologia intelectual" para orientar sua aplicação no processo de pesquisa e políticas. Portanto, em vez de manter o entendimento habitual da tecnologia como relacionada às ferramentas ou às máquinas, Bell recorreu ao termo tecnologia intelectual para 
se referir à substituição dos algoritmos (regras para solução de problemas) pelo juízo intuitivo nas políticas e na pesquisa.

As idéias de Bell sobre o novo papel do conhecimento nas economias das sociedades industriais avançadas forneceram uma das metáforas dominantes durante várias décadas, ajudando muitos cientistas sociais e formuladores de políticas a apontar o que caracterizava a mudança econômica. Além disso, suas idéias continuaram a influenciar o pensamento sobre sociedades/economias do conhecimento porque foram revigoradas e receberam um novo sopro de vida como resultado da extensão e elaboração de seu argumento central na trilogia de Manuel Castells, The information age: aconomy, society and culture (1996, 2000).

A trilogia de Castells, anunciada como a análise sociológica mais importante dos últimos tempos (Calhoun, 2000), apresenta três linhas argumentativas principais. A primeira é uma continuação do argumento de Bell de que o conhecimento (nos termos de Castells, geração, processamento e transmissão de informações) suplantou a terra, o trabalho e o capital como fonte fundamental de produtividade e poder. Castells amplia sua análise apresentando mais duas proposições sobre esse novo paradigma: ele é "global" e "em redes"'. Devido ao fato de ter escrito 20 anos depois de Bell, Castells concentra-se na valorização da tecnologia da ciência como Tecnologia da Informação e Comunicação - TIC - e seu impacto na sociedade, em vez de se concentrar na contribuição da tecnologia intelectual para o desenvolvimento econômico. Castells argumenta que as TICs caracterizam-se por:

... capacidade sem precedentes de armazenamento de memória e velocidade de combinação e transmissão de bits... [assim, oferecem] ... flexibilidade, feedback, interação e reconfiguração de dados [e] comunicação on-line consideravelmente maiores, além de flexibilidade de texto, o que permite a ubiqüidade na programação do tempo/espaço. (2000, p.30)

Desse modo, Castells introduz uma nova dimensão ao argumento original de Bell. Ele afirma que o emprego generalizado da TIC resultou na emergência

I. Uma vez que o foco deste capítulo é o novo papel do conhecimento nas economias das sociedades industriais avançadas, concentrei-me somente nos primeiros argumentos de Castells sobre a sociedade em rede. 
de um novo paradigma econômico - uma economia "informacional", cujas características centrais são a crescente demanda e produção de informação. A razão para essa demanda por informação é a dupla mudança que ocorreu no princípio do desenvolvimento econômico nas sociedades industriais avançadas (Castells, 1996, p.61-65). A primeira é a mudança de um modo de produção cujo objetivo principal era maximizar a produção para gerar mais-valia para um "modo informacional de desenvolvimento" preocupado com o desenvolvimento tecnológico e a geração de dados. A segunda é uma conseqüência lógica da primeira: o acúmulo constante de riqueza, por meio da transformação contínua das próprias tecnologias existentes e das TICs, significa que o sucesso na economia global depende da geração, do processamento e da aplicação de informações para melhorar o desempenho empresarial.

Portanto, em suma, o elo comum entre Bell e Castells é que ambos aceitam que o conhecimento tem importância fundamental para o desenvolvimento econômico nas sociedades industriais avançadas. Contudo, enquanto Bell concentrou-se exclusivamente na aplicação da ciência como estímulo à prosperidade econômica, Castells está preocupado principalmente com a aplicação tecnológica da ciência na forma de TIC e com a aplicação dos dados gerados pela TIC.

\section{O CONHECIMENTO TÁCITO COMO CONDIÇÃO SINE QUA NON DA ECONOMIA DO CONHECIMENTO}

A relação entre ciência e sociedade que está no cerne das colocações de Bell sobre o papel do conhecimento teórico na economia, e que em parte subjaz às idéias de Castell sobre a ligação entre a TIC e a informação, mudou durante a segunda metade do século passado de uma forma que eles aparentemente não reconhecem. Em vez de conceber a ciência como a principal fonte de "ilustração" e "inovação tecnológica", muitos cientistas sociais consideram-na em termos cada vez mais modestos e instrumentais (Osborne, 1998). Essa mudança no status da ciência pode ser atribuída a vários fatores:

- o surgimento da "tripla hélice" entre as universidades, a indústria e o Estado que, de maneira significativa, ampliou a gama de grupos de interesse preocupados com a produção de conhecimento nas sociedades industriais avançadas (Etzkowitz e Leydesdorff, 1997); 
- o processo de concorrência global que coloca ênfase na "performatividade" do conhecimento, isto é, sua capacidade instrumental de resolver problemas cotidianos (Lyotard, 1988);

- o aumento dos "riscos" associados à exploração comercial da ciência que têm levado as sociedades a suspeitar da ciência e a contestar suas pretensões de conhecimento (Beck, 1992).

Manifestação dessa nova relação entre ciência e sociedade tem sido o debate em outras áreas das ciências sociais - por exemplo, os estudos sobre gestão e políticas científicas - sobre a emergência de um novo modo de produção de conhecimento, uma nova concepção de conhecimento e sua contribuição para a sociedade/economia do conhecimento.

Michael Gibbons et al. oferecem uma das explicações mais controversas sobre a ascensão dos novos modos de produção de conhecimento. Eles distinguem o Modo I - pesquisa vinculada às disciplinas do conhecimento realizada em universidades - e o Modo 2 de conhecimento - modos de conhecimento heterogêneos e transdisciplinares criados em "contextos de aplicação" e "caracterizados por um fluxo constante, num ir-e-vir entre o fundamental e o aplicado, entre o teórico e o prático" (1994, p. | 8).

Essa nova forma de conhecimento é, de acordo com Gibbons et al. ( 1994 , p.24), uma "mistura" de componentes codificados e tácitos. Essa distinção foi cunhada por Polanyi ( 1958) para revelar as limitações filosóficas de se conceber o conhecimento científico em termos puramente formais, abstratos, e deixando de reconhecer o "elemento pessoal" do conhecimento científico. Gibbons et al. se valem da distinção entre o conhecimento codificado e o tácito para identificar as características distintivas do Modo 2 de conhecimento. Eles argumentam que é a dimensão tácita do conhecimento dos cientistas que lhes permite reconfigurar o "conjunto diverso dos recursos de conhecimento" disponível nas comunidades de profissionais de acordo com o problema em questão.

Essa ênfase no conhecimento tácito muda o locus da P\&D. Em vez de ser vista como um processo exógeno realizado em laboratórios universitários, a P\&D passa a ser concebida como um processo endógeno realizado nas empresas. Da perspectiva de Gibbons et al. (1994), portanto, é o conhecimento tácito que é menos suscetível à codificação, e não o conhecimento codificado que fornece às empresas as capacidades particulares que lhes atribuiriam van- 
tagem competitiva na economia global. Desse modo, sobreviver na economia global implica, portanto, a descoberta, por parte das empresas, das configurações do conhecimento tácito que lhes conferirão vantagem comercial de forma recorrente.

A idéia de que as empresas constituem locais de inovação não é uma proposição inteiramente nova. Autores que escrevem sobre ciência de gestão, como Drucker (1969), Penrose (1959) e Nelson e Winter (1972), foram os primeiros a ressaltar, na década de 1960, que as empresas eram depositárias de tipos de conhecimento bastante específicos e que elas, em maior ou menor grau, eram capazes de explorá-los com êxito. Essa "dimensão epistemológica" das atividades das empresas, isto é, o modo pelo qual elas contribuem para o maior volume de idéias sobre o que constitui a criação e o compartilhamento do conhecimento, foi analisado em profundidade por Nonaka e Takeuchi (1995). Da perspectiva desses autores, um conhecimento novo não é criado exclusivamente por cientistas, nem por meio do processo impessoal que os cientistas consideram característica fundamental da metodologia científica. $\bigcirc$ conhecimento pode ser criado por profissionais que facilitam uma "espiral de interações" entre o conhecimento explícito - nos termos de Nonaka e Takeuchi, informação comunicada oralmente ou em forma escrita - e o conhecimento tácito que desenvolveram de maneira intuitiva e naturalista no trabalho.

Nonaka e Takeuchi, como Gibbons et al., invocam os argumentos de Polanyi sobre a "dimensão tácita" para justificar suas idéias sobre o papel crucial do conhecimento tácito para o desenvolvimento econômico. Com base nas evidências de um estudo de caso sobre o desenvolvimento de um novo produto em empresas japonesas, Nonaka e Takeuchi (1995) afirmam que a espiral de interações entre o conhecimento tácito e aquele codificado pelos funcionários constitui um processo de criação de conhecimento quintessencial. Isso possibilita que o conhecimento tácito seja explicitado à medida que representamos compreensões intuitivas na forma de "metáforas, analogias, conceitos, hipóteses ou modelos". Uma vez que o conhecimento tácito alcançou esse estado de explicitação, pode ser compartilhado e tornar-se parte de um repertório de conhecimento mais amplo que os funcionários usam para transformar o projeto e o fornecimento de produtos e serviços.

Em oposição a Bell e a Castells, que aceitavam a primazia do conhecimento teórico, embora se concentrassem em diferentes aspectos de sua 
produção e aplicação na economia, Gibbons et al. e Nonaka e Takeuchi dão mais ênfase ao conhecimento tácito como recurso primordial do conhecimento. A principal razão para a apresentação dessas diferentes explicações sobre o tipo de conhecimento exigido na economia do conhecimento é o fato de Bell, Castells, Stehr, Gibbons et al. e Nonaka e Takeuchi adotarem visões do conhecimento fundamentalmente diferentes, concepções científico-realistas e pós-modernas, respectivamente.

\section{CONCEPÇÕES CIENTÍFICO-REALISTAS E PÓS-MODERNAS SOBRE A ECONOMIA DO CONHECIMENTO}

É amplamente aceito que as opiniões de Bell sobre a primazia do conhecimento teórico baseiam-se em uma pressuposição não problematizada sobre a natureza da investigação e do conhecimento científicos (Muller, 2000; Stehr, 1994). Isso leva Bell a aceitar duas idéias sobre o conhecimento teórico: que ele é independente de condições contingentes; e que sua aplicação é um processo linear (Stehr, 1994, p.67). Assim, ao aceitar a realidade como dado, a legitimidade do conhecimento científico e a existência de um fluxo linear entre a descoberta e a aplicação de idéias científicas, Bell pôde endossar que o conhecimento constitui o "princípio axial" do desenvolvimento econômico. Castells, diferentemente de Bell, não se propõe a realizar nenhuma discussão epistemológica sobre o status do conhecimento, uma vez que acreditava não ter "nenhuma razão imperiosa" para aperfeiçoar a definição de conhecimento do próprio Bell. O resultado final desse silêncio sobre as questões epistemológicas é que Castells acaba, por omissão, compartilhando uma posição filosófica semelhante à de Bell sobre o caráter do conhecimento (Muller, 2000, p.276-277).

Ao adotarem uma versão um tanto pesada do realismo científico, Bell e Castells desconsideram diversas questões sobre o caráter e a aplicação do conhecimento que são fundamentais para suas próprias teses. A primeira questão é a de que ambos aceitam o conhecimento científico como um dado, e não como produto de influências externas ou de debates no interior das disciplinas. A implicação desse pressuposto manifesta-se no trabalho de cada um dos autores de diferentes modos. Bell vale-se do conhecimento como uma variável independente para explicar as mudanças ocorridas nas sociedades 
pós-industriais em termos do aumento verificado do componente de conhecimento no Produto Interno Bruto das nações. Castells, por sua vez, usa as informações como uma variável independente para explicar a ligação entre o emprego da TIC e a produtividade como "o conhecimento agindo sobre o conhecimento". A segunda questão é que ambos tratam a informação e o conhecimento teórico como se fossem objetos culturais discerníveis que podem ser facilmente adquiridos e aplicados para gerar soluções para os problemas. Para Bell, o conhecimento teórico tem qualidades intrínsecas que podem ser facilmente aplicadas para resolver problemas sociais ou econômicos, desde que a aplicação do conhecimento seja orientada pelos algoritmos intelectuais adequados (Schiller, 1997). Para Castells, por sua vez, a informação gerada pela TIC é um recurso maleável e é uma questão bastante direta transformála em conhecimento utilizável para fomentar o desenvolvimento econômico (Webster, 1997, p.120).

Uma conseqüência de se aceitar o pressuposto científico-realista sobre a natureza de dado e a aplicabilidade do conhecimento científico é que Bell e Castells supõem que a ciência, por si só, seja o "motor" a impulsionar as mudanças tecnológicas e sociais. Ao fazê-lo, eles implicitamente adotam a noção que Dennett ( 1987 ) denominou transformação social com "estratégia de projeto". Eles pretendem que o projeto das características tecnológicas de qualquer sistema seja o responsável por produzir um conjunto específico de resultados, melhorar e garantir os resultados desse sistema, o qual é basicamente responsável por gerar novas informações, produtos e serviços. Portanto, Bell e Castells sustentam que o processo de modernização pode ser medido observando-se o impacto transformativo da ciência nas sociedades industriais avançadas. Cada um dos autores ressalta suas características estruturais, a produção final dos acréscimos do conhecimento (isto é, novos produtos e serviços) no interior da economia e os efeitos transformadores do conhecimento científico sobre os diferentes aspectos da vida cultural e social, da vida e identidade pessoais, da organização industrial e da expansão de mercado etc.

É perfeitamente razoável que Bell e Castells afirmem que a modernização pode ser medida até certo ponto observando-se o impacto transformador da ciência e da tecnologia nas sociedades industriais avançadas. Há muito tempo se reconhece que sempre houve uma relação próxima entre a especialização tecnológica, culturas tecnológicas e desenvolvimento tecnológico nas econo- 
mias capitalistas (Noble, 1979). Contudo, para entender por que as mudanças identificadas por Bell e Castells ocorreram, é necessário levar em conta, de forma mais explícita, a contribuição da cultura ao desenvolvimento e à aplicação da ciência e da tecnologia. Antes de voltar-se para essa questão, o texto destaca as concepções pós-modernas do conhecimento que caracterizam o trabalho de Gibbons et al. e de Nonaka e Takeuchi.

A influência pós-moderna pode ser percebida nos trabalhos de Gibbons et al. pelo tom polêmico que permeia a observação dos autores de que a emergência do Modo 2 de conhecimento fundamentalmente questiona todo o edifício do realismo científico porque, ao contrário do Modo I, ele é incompleto:

... não mais no sentido convencional de que acabará sendo suplantado por uma ciência superior (para os popperianos) ou por um novo paradigma científico (para os kuhnianos), mas também no sentido de que é severamente contestado (e não mais no ambiente controlado dos colegas cientistas, mas na arena mais ampla); em segundo lugar, essa mudança implica renegociar e reinterpretar essas fronteiras. (Nowotony, 200 I, p. 199)

Para Gibbons et al., essa contínua diminuição do isolamento social da ciência constitui prova incontroversa de uma tendência que dará continuidade a uma demanda crescente pelo Modo 2 de conhecimento não somente nos campos científicos, mas também, de forma mais ampla, na sociedade. Além disso, a aceitação geral de uma concepção do conhecimento mais pluralista também alimentará, de acordo com Gibbons et al., uma demanda por novos padrões em relação aos quais o conhecimento poderá ser avaliado; esse desenvolvimento consolidará a mudança em direção a uma "sociedade Modo 2".

À primeira vista é mais difícil identificar a influência pós-moderna no trabaIho de Nonaka e Takeuchi. Os autores consideram sua teoria da conversão do conhecimento como uma tentativa de superar um dos principais pressupostos científico-realistas: o de que a mente e o mundo estão separados; e evitam, em seus textos, quaisquer referências explícitas ao pós-modernismo. Por essa razão, eles, e outros acadêmicos familiarizados com seu trabalho, podem ficar surpresos, ou mesmo chocados, em descobrir que seu trabalho é interpretado como se manifestasse uma sensibilidade pós-moderna e permanecesse 
enredado no dualismo. Contudo, a evidência da inflexão pós-moderna do pensamento de Nonaka e Takeuchi é clara em sua defesa de uma concepção de conhecimento pluralista.

Em um esforço resoluto para se distanciar do "decoro epistemológico" (Shapin, 1994), que é a característica dominante do modo de produção de conhecimento científico-realista, Nonaka e Takeuchi (1 995, p.64) enfatizam os "aspectos subjetivos, corpóreos e tácitos" inevitáveis da produção de conhecimento. Assim, sustentam que sua espiral da conversão do conhecimento é tão válida como metodologia científica quanto um método para produzir conhecimentos novos no contexto do local de trabalho, e que o conhecimento resultante é, por sua vez, tão válido quanto a ciência para apoiar as vantagens competitivas das organizações na economia do conhecimento.

Ao defenderem o argumento sensato de que as organizações não contam unicamente com a ciência para assegurar sua vantagem competitiva e que a produção e a aplicação do conhecimento são determinadas por fatores contextuais, Nonaka e Takeuchi introduzem um argumento radicalmente novo sobre o conhecimento tácito e teórico. Os autores, ao pretenderem que estas são formas igualmente importantes de conhecimento na economia do conhecimento, alinham-se à tradição pós-moderna de conferir simetria a todas as formas de conhecimento e a todos os métodos de produção de conhecimento. Enquanto os pós-modernos tendem a citar Nietzsche e sua rejeição da idéia de verdade fundamental e sujeito racional, para estabelecer a base filosófica a fim de conferir simetria ao conhecimento (Ward, 1996, p. 18), a justificativa para tornar simétricos o conhecimento tácito e o conhecimento científico está, segundo Nonaka e Takeuchi, no trabalho de Polanyi. Como veremos, embora Polanyi não forneça a justificativa para que o conhecimento seja dotado de simetria, suas idéias sobre a relação entre a prática e a cultura científicas abrem caminho para uma explicação cultural da relação entre o conhecimento, a sociedade e a economia do conhecimento.

\section{CONHECIMENTO, CULTURA E ECONOMIA DO CONHECIMENTO}

Quando Polanyi recorreu pela primeira vez à noção de conhecimento tácito, sua preocupação era preparar o terreno para uma compreensão holística do conhecimento científico, em vez de introduzir mais uma categoria 
do conhecimento (Thorpe, 1999). Simplificando, seu argumento era de que a maneira como os cientistas usavam e desenvolviam o conhecimento não poderia ser explicada exclusivamente pela referência à sua base proposicional. Daí sua famosa frase: "sabemos mais do que podemos expressar" (Polanyi, 1966, p.4). Para Polanyi, esse era o ponto de partida natural para abordar a relação entre os elementos "articuláveis" e "inarticuláveis" do conhecimento. Assim, diferentemente de Nonaka e Takeuchi, o conhecimento tácito não é, para Polanyi, uma forma de conhecimento informal, incipiente ou obscura, cuja natureza exige que seja explicitado para ser entendido ou útil na prática; sua formulação era muito mais sutil.

Polanyi ( 1958) também reconheceu que a ciência sempre teve uma dimensão tácita e que o desempenho competente no mundo da ciência, assim como na arte ou em qualquer outro campo, não se alcança simplesmente seguindo regras formuladas explicitamente com base no conhecimento proposicional. "É preciso também que vários outros fatores, excluídos da formulação das regras, sejam levados em consideração na prática" (p.49). Polanyi invocou a idéia de "habitação" para explicar a imersão ou enculturação dos cientistas em um conjunto de pressupostos teóricos e habilidades físicas relacionadas ao seu campo disciplinar (Thorpe, 1999, p.25-35). Sua concepção da "habitação" envolvia uma transmissão tácita da cultura científica através da qual o significado é estabelecido na prática científica pelos modos senciente e sapiente².

O primeiro é uma forma claramente limitada de conhecimento tácito estabelecida à medida que os cientistas se tornam conscientes do impacto das ações práticas em seu corpo quando manipulam recursos de laboratório. O último é uma forma mais abrangente de conhecimento tácito que se estabelece à medida que os cientistas se tornam conscientes das implicações de seus pensamentos e ações quando geram hipóteses, identificam possíveis espaços de investigação e interpretam os resultados de suas experiências. Essa concepção sapiente pressupõe a interdependência entre o conhecimento teórico e o tácito (Guile, no prelo (a)). Assim, contrapondo-se à forma como é normalmente interpretado, Polanyi deu ênfase às dimensões interdependentes

2. Vali-me da discussão de Brandom (2000) sobre a diferença entre senciência e sapiência de duas formas: para esclarecer a relação que Polanyi afirmou existir entre o conhecimento teórico e o conhecimento tácito; e para estabelecer uma ligação com a distinção que Zuboff ( 1988) apresentou entre capacidade "orientada para a ação" e "intelectiva". 
do conhecimento científico, em vez de sustentar que havia dois tipos distintos de conhecimento (Seely Brown e Duguid, 200I).

Ao desconsiderar esse aspecto do argumento de Polanyi, Gibbons et al. e Nonaka e Takeuchi perdem de vista a originalidade de sua posição sobre a interdependência entre o conhecimento tácito e o teórico. Esse descuido tem conseqüências teóricas para as idéias desses autores sobre o conhecimento tácito, bem como para nossa compreensão sobre qual conhecimento é exigido na economia do conhecimento. Ao afirmar a maior importância do conhecimento tácito em relação ao conhecimento teórico, Gibbons et al. e Nonaka e Takeuchi rompem a ligação entre essas duas formas de conhecimento. Esse rompimento ocorre de maneira ligeiramente diferente em cada um dos casos. Ao privilegiar o conhecimento tácito dos cientistas em relação a seu conhecimento disciplinar, Gibbons et al. minimizam a dimensão em que os pensamentos e ações tácitos dos cientistas que trabalham em contextos transdisciplinares são respaldados e informados pelo conhecimento disciplinar que já adquiriram formalmente e, subseqüentemente, desenvolveram por meio de sua "habitação" em comunidades científicas.

Do mesmo modo, ao conceber o conhecimento tácito como se fosse uma forma de conhecimento intuitiva e inconsciente, desenvolvida pelos sentidos, Nonaka e Takeuchi acabam por afirmar que uma forma de conhecimento tácito bastante limitada é o recurso mais importante na economia do conhecimento. Contudo, uma leitura atenta do texto dos autores revela que o conhecimento tácito, que alegam ser o recurso vital do conhecimento, é tanto uma forma de "conhecimento pessoal", não compartilhado com os outros (Eraut, 2004), quanto uma forma de "conhecimento social", mantido pelas comunidades de prática no local de trabalho (Spender, 1996). Trata-se, em outras palavras, do conhecimento tácito sapiente, cuja característica distintiva é ser um recurso que permite aos cientistas e a outros profissionais inferir o que se origina do quê.

A ligação entre cultura, prática e inferência permite apresentar uma concepção radicalmente distinta da relação entre conhecimento teórico e tácito se comparada às idéias de Nonaka e Takeuchi e de Gibbbons et al. sobre essa relação. Um modo de ressaltar isso é fazendo referência à discussão clássica de Zuboff ( 1988 ) sobre os novos desafios da atuação em ambientes tecnológicos. Zuboff analisou a TIC no contexto de sua implementação, debruçando-se 
explicitamente sobre como o contexto organizacional, o objetivo gerencial e as estruturas de trabalho influenciam o emprego da tecnologia da informação nas empresas. Essa abordagem possibilitou-Ihe identificar o modo pelo qual a introdução da TIC pode alterar essencialmente a natureza do conhecimento e da habilidade em contextos comerciais e industriais. Ao fazê-lo, lança luz sobre como condições diferentes estimulam o desenvolvimento de diferentes tipos de conhecimento tácito ${ }^{3}$.

Zuboff introduziu os conceitos de capacidade "orientada para a ação" e "intelectiva" para abranger a natureza dos diferentes tipos de conhecimento e habilidades necessários ao trabalho com a tecnologia de máquinas em contraposição à tecnologia da informação. $O$ primeiro refere-se a um modo "experiencial" de desenvolvimento de capacidade geralmente adquirido por meio de um engajamento senciente no processo de trabalho anterior à introdução da TIC. O último refere-se ao modo de pensamento exigido quando se trabalha em ambientes mediados por computadores os quais envolvem a interpretação de dados simbólicos cujo significado não é um valor dado mas, ao contrário, deve ser construído.

Essas distinções permitiram-Ihe contrastar culturas tradicionais sensíveis ao trabalho e às práticas com a crescente "textualização do trabalho" introduzida pelo emprego da TIC em contextos comerciais e industriais. No mundo da competência orientada para a ação, o contexto da ação sensibiliza os funcionários com relação ao tipo de detalhes que devem procurar e ao tipo de dados que devem esperar. Nos ambientes mediados por computadores, por sua vez, os funcionários eram forçados a fazer perguntas sobre os dados gerados pela informatização do processo de trabalho, por exemplo "O que está acontecendo?" e "O que isso significa?" (Zuboff, 1988, p. 196). Responder a esse gênero de perguntas, que surgem do fato de se trabalhar em um meio simbólico, gera questões sobre o diálogo, a visualização, a colaboração e a disposição para assumir riscos no local de trabalho. Realizar o trabalho passou a depender, conforme conclui Zuboff (1988, p.95), mais da capacidade do "pensamento teórico" ou "sistêmico" para dar respaldo aos funcionários em

3. Minha interpretação de Zuboff é muito diferente de como seu texto foi lido por muitos outros cientistas sociais. Concentrei-me nas suas idéias a respeito de como diferentes condições estimulam o desenvolvimento de diferentes tipos de conhecimento tácito, ao passo que muitos outros autores concentraram-se nas implicações de sua análise para a organização de trabalho. 
sua necessidade de refletir sobre um meio simbólico que se apresenta eletronicamente e responder a esse meio, do que expressar conhecimento oriundo de experiência senciente.

A mudança na qualidade do conhecimento exigida para se trabalhar em ambientes informatizados é, contudo, de certa forma mais complexa do que pode parecer à primeira vista. Não se trata simplesmente da substituição de um tipo de conhecimento - tácito - por outro conhecimento - codificado ou explícito. Zuboff (1988, p. 192) reconhece que o conhecimento tácito continua a ter um papel no desenvolvimento da competência intelectiva. Uma das principais razões por que o conhecimento tácito ainda é importante, segundo Zuboff, é que nossa memória de longa duração baseia-se na apreensão do significado, e não na resposta a contextos visuais ou verbais precisos. Isso significa que nosso:

domínio intelectivo dependerá de sermos capazes de desenvolver um conhecimento tácito que facilite o reconhecimento de nossas alternativas de decisão e libere a mente para o tipo de insight que pode resultar em inovação e melhoria. Esse reconhecimento tácito depende, primeiramente, de sermos capazes de elaborar explicitamente o significado dos padrões e relações observados nos dados. (Zuboff, 1988, p. 192)

Em outras palavras, só é possível interpretar dados textuais sobre o desempenho dos sistemas tecnológicos e responder às interpretações dos outros quando sabemos qual linha de ação decorre de sabermos do que se trata. Isso implica entender o que Brandom (2000, p. I 58) chama de forma "representacional" e "inferencial" de um texto ou de uma enunciação; isto é, a capacidade de articular o que está acontecendo no processo de produção, comunicar esse entendimento aos outros e envolver-se em discussões coletivas sobre suas implicações.

Assim, diferentemente de Gibbons et al. e Nonaka e Takeuchi, Zuboff identifica o modo pelo qual diferentes contextos tecnológicos facilitam o desenvolvimento de diversos tipos de competências e conhecimentos. Em contextos tradicionais, desenvolvemos competências orientadas para a ação que dependem de uma forma senciente de conhecimento tácito, ao passo que em contextos baseados na TIC desenvolvemos competências intelectivas 
baseadas em uma forma sapiente de conhecimento tácito que se soma a nossos conhecimentos teóricos e práticos anteriores. Assim, Zuboff, do mesmo modo que Polanyi, estabelece não somente a interdependência dos conhecimentos teórico e tácito, mas também que a capacidade de interpretar, compartilhar e produzir conhecimento é desenvolvida à medida que recorremos a ambos os tipos de conhecimento ao estabelecermos julgamentos sobre o que está acontecendo no processo de produção.

Isso permite à autora avançar um passo na ligação entre a cultura, a prática e a produção do conhecimento em relação ao que fizeram Gibbons et al. e Nonaka e Takeuchi. Ela reconhece que certas condições culturais devem ser preenchidas para que os funcionários desenvolvam o conhecimento tácito associado à competência intelectual. A primeira condição é proporcionar alguma forma de "capacitação" para ajudar os funcionários a entender os dados apresentados pelo sistema tecnológico. A segunda condição são as oportunidades de usar a TIC no local de trabalho para: identificar o significado dos padrões e relações nos dados; construir sentido por meio do diálogo e da participação nas culturas do local de trabalho; e aplicar quadros conceituais para interpretar os dados com o objetivo de esclarecer e resolver problemas.

Suas idéias nos deixam, portanto, com o espinhoso problema de aprender como estabelecer relações entre as diferentes formas de conhecimento. Em outro texto, argumentei que é possível formular uma teoria holística do conhecimento na qual essas duas formas de conhecimento, aparentemente díspares, podem ser integradas (Guile, no prelo). Contudo, em termos práticos e sociais, pode-se argumentar que podem ser estabelecidas ligações entre essas duas concepções do conhecimento por meio do conceito de culturas de conhecimento.

\section{CULTURAS EPISTÊMICAS E ECONOMIA DO CONHECIMENTO}

A importância da relação entre produção de conhecimento e cultura foi avaliada apenas recentemente no debate sobre a economia do conhecimento. Isso se deve, em parte, a autores como Knorr Cetina terem começado a atribuir importância a um aspecto desse debate até então negligenciado - a contribuição do conhecimento ou das culturas epistêmicas às economias e sociedades do conhecimento. $\bigcirc$ papel crescente dos sistemas especialistas, como ressalta 
Cetina (1997, p.8), não resulta somente na presença maciça dos produtos informacionais e tecnológicos dos processos de conhecimento, mas também significa que as culturas epistêmicas "teceram e esparramaram sua teia sobre a sociedade". O conceito de uma "cultura epistêmica" refere-se a:

aqueles amálgamas de arranjos e mecanismos - unidos pela afinidade, necessidade e co-incidência histórica - que, em um determinado campo, constituem a forma como sabemos o que sabemos. As culturas epistêmicas são culturas que geram e garantem o conhecimento; e a instituição do conhecimento por excelência em todo o mundo ainda é a ciência. (Cetina, 1997, p.8)

Assim, da perspectiva de Knorr Cetina:

Uma sociedade do conhecimento (economia do conhecimento) não é simplesmente uma sociedade [economia] com mais especialistas, mais apetrechos tecnológicos, mais interpretações de especialistas, (é também) uma sociedade [e economia] permeada de culturas do conhecimento, todo o conjunto de estruturas e mecanismos que servem ao conhecimento e se desdobram com sua articulação ${ }^{4}$ (1997, p.8)

Cetina emprega duas abordagens distintas, mas relacionadas, para ilustrar o papel fundamental desempenhado pelas culturas epistêmicas na produção e na aplicação da ciência. Uma delas trata da comparação da forma como dois campos científicos - física de alta energia (HEP) e biologia molecular - organizam suas estratégias de aquisição de conhecimento. Isso lhe permite revelar a ligação entre a prática científica, isto é, a variedade na agregação de padrões e dinâmicas verificada nas práticas científicas especializadas, o modo pelo qual diferem de contexto para contexto e seus respectivos resultados científicos. Além disso, decorre do argumento de Cetina, embora ela não o discuta explicitamente, que o modo pelo qual os cientistas são enculturados nessas práticas

4. Há um paralelo entre as preocupações de Knorr Cetina com o estabelecimento de uma definição mais ampla do papel do conhecimento nas "sociedades do conhecimento" e a preocupação deste capítulo em estabelecer uma definição mais ampla do papel do conhecimento na economia. Por essa razão, destaquei os paralelos entre os respectivos argumentos, inserindo as referências à economia do conhecimento no texto original da autora. 
epistêmicas Ihes possibilita inferir conjuntamente as implicações do processo de pesquisa científica.

É a disseminação das culturas epistêmicas, de acordo com Cetina, que faz com que as economias/sociedades do conhecimento se distingam de forma marcante dos tipos de economias/sociedades que as precederam. Ela desenvolve essa idéia argumentando que algumas das formas estruturais tradicionalmente encontradas nas culturas epistêmicas estão gradativamente se tornando predominantes nas economias das sociedades industriais avançadas. O exemplo paradigmático é, de acordo com Cetina ( 1997, p.8), uma extensão das "relações orientadas para os objetos" que são características de contextos científicos. A característica definidora dessas relações orientadas para os objetos em contextos científicos é a interação entre o aspecto de "geração de perguntas" do processo de pesquisa e o uso crescente de objetos tecnológicos para estabilizar esse processo e fornecer "respostas" às perguntas das pesquisas. Embora na ciência esse processo seja estruturado e guiado pelo campo disciplinar no qual os cientistas estão trabalhando, Cetina argumenta que há cada vez mais evidências da disseminação dessas relações orientadas para o objeto em outros campos que não o científico.

Ela explora as implicações de seu argumento por meio de uma análise detalhada da operação dos mercados financeiros globais e identifica a cultura epistêmica distintiva e formas de atividades epistêmicas associadas ao comércio (Bruegger, Cetina, 2000). A autora conclui que os negociadores estão constantemente envolvidos em uma luta para compreender a operação dos mercados financeiros por meio de um processo de coleta e descarte das informações relevantes. Isso envolve seu questionamento contínuo sobre o que está ocorrendo no mercado e a realização de um esforço determinado para tentar encontrar informações sobre o provável desempenho dos mercados financeiros. Assim, os mercados financeiros (e, por extensão, outras formas de trabalho que se baseiam na coleta e descarte de informações) são, teoricamente, objetos de conhecimento para quem deles participa.

Essas observações sobre o vazamento das culturas epistêmicas sobre outros campos ocupacionais que não o científico levantam diversas questões não abordadas por Cetina. A primeira delas é que, enquanto para a ciência o processo de "geração de perguntas/fornecimento de respostas" já foi estruturado e serviu de orientação para o campo disciplinar no qual os cientistas estão trabalhando, 
o quadro de referências para orientar esse processo epistêmico nos outros campos profissionais ainda precisa ser estabelecido. Trabalhar além dos limites definidores das áreas aceitas como conhecimento especializado em equipes transdisciplinares e com colaboração entre profissionais pressupõe novos tipos de capacidade profissional. Isso pode ser definido como a capacidade de apresentar dados a especialistas em diferentes campos, bem como aos seus próprios clientes, não familiarizados com seu significado, responder à interpretação que fazem desses dados, estabelecer ligações entre as respectivas interpretações e chegar a um acordo a respeito das linhas de ação adequadas (Guile, no prelo). Essas capacidades são de uma importância muito distinta da ênfase conferida atualmente pela política educacional ao domínio do conhecimento disciplinar e à aquisição de competências fundamentais. Além disso, apresentam questões novas e fundamentalmente diferentes sobre o modo como a política educacional deve apoiar o desenvolvimento da economia do conhecimento.

A segunda questão é que a ligação entre as culturas do conhecimento e o trabalho do conhecimento pode ser mais complexa e menos automática e inevitável do que supõe a metáfora do "derramamento" de Cetina. Isso sugere que os limites do conceito de economia/sociedade do conhecimento devem ser estabelecidos de forma mais rígida. Em vez de descrever a economia sui generis como uma economia do conhecimento, pode ser mais útil estabelecer uma diferença entre as organizações e as redes, semelhante à dos setores industriais que estabeleceram culturas que estimulam a produção do conhecimento. Também pode ser útil para os pesquisadores e formuladores de políticas identificar as precondições epistêmicas necessárias para estimular a disseminação de culturas de conhecimento. Isso lhes permitiria diferenciar mais cuidadosamente o papel da educação e dos negócios no estímulo ao crescimento de culturas epistêmicas. Permitiria, ainda, que os formuladores de política reconsiderassem e reavaliassem a suposta ligação entre a política educacional e a economia do conhecimento.

\section{AS IMPLICAÇÕES EDUCACIONAIS DO “CONHECIMENTO” PARA A ECONOMIA DO CONHECIMENTO}

Desde o início da década de 1990, a política educacional tem-se pautado cada vez mais pela ligação entre educação e competitividade nacional 
(Brown, Lauder, 1991). Essa ligação sofreu novas alterações nas políticas educacionais recentes do Reino Unido e da União Européia. Em ambos os casos, o conceito de economia do conhecimento foi empregado em dois sentidos: como uma visão de atividade econômica futura e como embasamento para políticas de aprendizagem ao longo da vida. Essa dupla ênfase pode ser vista muito claramente nas palavras de David Blunkett, então secretário de Estado para Educação do Reino Unido, que observou: "Aprender é a resposta para a prosperidade - para cada um de nós individualmente e para a nação como um todo. Os investimentos no capital humano serão a base para o sucesso na economia global baseada no conhecimento do século 2l" (DfEE, 1998, p.7).

Além disso, uma ligação semelhante entre a educação e a economia do conhecimento é apresentada no Memorando sobre Aprendizagem ao Longo da Vida, da União Européia, que declara que o objetivo dos formuladores de políticas educacionais da UE deverá ser o de identificar: "estratégias coerentes e medidas práticas com a finalidade de estimular a aprendizagem ao longo da vida para todos, de modo a ajudar a Europa a tornar-se a sociedade baseada no conhecimento mais dinâmica e competitiva do mundo" (EC, 200 I , p.3).

Um dos resultados de se tomar como dada a ligação entre conhecimento, aprendizagem e desenvolvimento econômico é que os formuladores de políticas seguiram Bell e Castells e adotaram uma concepção de estratégia de implementação de políticas. Eles presumiram que medidas políticas, como o aumento da participação, quadros para garantir a qualidade da aprendizagem e padrões de qualificação, podem ser "planejadas" para produzir o conjunto de resultados almejado. Uma conseqüência dessa ênfase nos quadros é que, conforme Moore e Young (200I, p.445) cautelosamente observaram, não só há pouca clareza nas políticas educacionais sobre o tipo de conhecimento exigido, como também há pouca discussão sobre como esse conhecimento deveria ser adquirido. As implicações dessa questão não foram levadas em conta em termos de política educacional. Elas são profundas, contudo. Talvez o exemplo do ensino superior possa ilustrar esse ponto.

ensino superior é visto como o foco da economia do conhecimento. Contudo, ele também é marcado pela distinção entre os dois tipos de conhecimento, e não por uma apreciação de sua interdependência. Um modo de ilustrar essa questão é distinguindo entre diversas concepções do 
conhecimento - a "tradicional", a "utilitária" e a "pós-moderna" ${ }^{5}$, que estão incorporadas na política educacional para o ensino superior. A concepção tradicional representa uma combinação de idéias. Endossa a visão de que há um determinado corpus de conhecimentos fundamentais (isto é, o conhecimento científico e literário) que deve fazer parte do currículo e que as universidades têm a responsabilidade de transmitir. Consolida também o status fundacional e canônico das disciplinas ao aceitar que elas e o método científico constituem a única base para a realização de pesquisas. A concepção "utilitária" concebe o conhecimento como meio para um fim. Dessa perspectiva, considera-se o papel do currículo universitário como uma contribuição à realização da "forma de sociedade" particular desejada pelos formuladores de políticas, ao passo que o papel da pesquisa é considerado como de amparo ao crescimento da industrialização. Enfim, a concepção pós-moderna baseia-se na idéia de que o mundo e o conhecimento são sempre um produto de diferentes pontos de vista ideológicos. Para os pós-modernos, qualquer currículo baseado nas concepções tradicionais e utilitárias baseia-se em pressupostos essencialmente arbitrários sobre conhecimento e cultura.

Assim, desse posicionamento resulta que os valores, os interesses e as perspectivas que informam o conhecimento "local" ou "tácito" deveriam receber o mesmo status nas universidades.

Essas três modalidades podem ser usadas para revelar as tensões relativas ao conhecimento gerado no ensino superior, à medida que os formuladores de políticas passaram a exercer pressão contínua sobre as universidades para que adequassem seus currículos à economia do conhecimento. Uma das tensões é resultado do confronto entre a firme ênfase da QAA [Agência de Garantia de Qualidade do Ensino Superior] na especificação dos conhecimentos da disciplina que deverão ser ensinados e avaliados nos cursos universitários, bem como sua determinação em garantir que todos os cursos façam com que os alunos desenvolvam competências essenciais. A primeira perpetua a idéia de que todo conhecimento baseia-se em formas de generalização (isto é, representações

5. Essas concepções do conhecimento foram em parte influenciadas pelas modalidades do conhecimento formuladas por Moore e Young (200I) para esclarecer as diferentes concepções do conhecimento que informam os debates atuais sobre o currículo 14-19. Elas são, em parte, influenciadas por minhas interpretações dos argumentos de Delanty (200 I) sobre as "mudanças cognitivas" ocorridas nas sociedades industriais. 
abstratas do mundo) radicadas em tradições disciplinares ou multidisciplinares bem estabelecidas, a fim de que possam usar o conhecimento em modos tradicionalmente esperados como, por exemplo, em trabalhos escritos. Em contrapartida, a última supõe que qualquer forma de conhecimento seja maleável, desde que os alunos tenham desenvolvido as principais competências necessárias para aplicá-las em diferentes contextos. Assim, atualmente se espera que as universidades ajudem os alunos a adquirir conhecimentos disciplinares, assim como os capacitem a adquirir competências descontextualizadas (isto é, competências centrais) em situações com contextos específicos (isto é, palestras, laboratórios, estágios) (Guile, 200 I). Isso coloca as qualificações em uma posição delicada: elas devem garantir padrões de conhecimento adquiridos e servir como medida alternativa a ser usada pelos empregadores para avaliar o desempenho provável dos alunos no local de trabalho.

Uma segunda tensão refere-se ao confronto entre a ênfase tradicional na aquisição do "conhecimento disciplinar" e a ênfase pós-moderna das políticas educacionais para o ensino superior na heterogeneidade do conhecimento representada por medidas para reconhecer o conhecimento "experiencial" e/ou "tácito" anterior e reconhecer a diversidade cultural do discurso. Essa tensão coloca o aluno em uma posição contraditória. Por um lado, adquirir conhecimento disciplinar pressupõe o desenvolvimento de capacidades para compreender o sistema de conexões que estruturam e informam as disciplinas. Por outro lado, a importância de compreender essas conexões parece ser negada pela valorização do conhecimento experiencial e tácito avaliado mediante diários e portfólios de aprendizagem.

Como resultado final, essas tensões impõem aos alunos um sério dilema pedagógico (Guile, no prelo a). Esse dilema, segundo Prawat (1999, p.60), pode ser definido como uma questão de "concentrar a atenção" ou "dividir a atenção". Os alunos oscilam entre ter de concentrar sua atenção em especificações de programas claramente definidas com base nas disciplinas do conhecimento ou dividir sua atenção em inúmeras aptidões a fim de se envolver e responder às formas heterogêneas de conhecimento atualmente aceitas no ensino superior.

A pressão para modernizar o ensino superior apresentou as duas interpretações do conhecimento à economia do conhecimento que Bell, Castells, Gibbons et al. e Nonaka e Takeuchi colocam no centro do currículo do ensino 
superior sem reconhecer a inadequação epistemológica dessas interpretações. Ironicamente, a tentativa de modernizar o currículo do ensino superior e de adotar uma posição mais inclusiva com relação às formas de conhecimento ensinadas e reconhecidas priva os alunos de qualquer maneira de relacionar essas diferentes formas de conhecimento. Todavia, isso vem ganhando visibilidade, uma vez que a discussão das culturas epistêmicas revelou que a economia do conhecimento tem explicitado a já antiga interdependência entre o conhecimento teórico e tácito e que isso pressupõe pedagogias que auxiliem os alunos a mediar diferentes formas de conhecimento, e não oscilar entre elas (Guile, no prelo).

\section{CONCLUSÃO}

Neste artigo argumentou-se que os cientistas sociais que divulgaram a tese da economia do conhecimento não conseguiram compreender os vínculos entre as duas concepções de conhecimento na economia do conhecimento. Isso os levou a oferecer explicações conflitantes quanto ao conhecimento teórico ou tácito ser o recurso econômico mais importante na economia do conhecimento. Em seguida, o texto argumentou que, ao tratar o conhecimento teórico e tácito como tipos de conhecimento distintos e separados, os cientistas sociais não conseguiram detectar o que distingue a economia do conhecimento em dois sentidos. Sociologicamente, não foram capazes de compreender a interdependência entre conhecimento e cultura; filosoficamente, não deram conta de como seria possível considerar esses tipos de conhecimento como interdependentes.

Em termos de política educacional, ao menos duas conseqüências decorrem desse tipo de análise. A primeira relaciona-se à estruturação do conhecimento no ensino superior; a segunda, à necessidade de se levar em conta a maneira pela qual os educadores podem estimular as capacidades adequadas para que os alunos participem das culturas de conhecimento. Contudo, em vista da base cultural subjacente à economia do conhecimento, questões importantes precisam ser colocadas no que diz respeito ao tratamento das qualificações como uma medida substitutiva para o conhecimento exigido nessa economia. Nesse sentido, conhecimento e cultura não podem ser testados diretamente da forma pretendida por baterias de exames e testes. Ao contrário, deveria ser 
dada mais ênfase ao desenvolvimento de formas de cognoscibilidade para um modo de vida particular no qual a colaboração e a comunicação fossem vistas como aspectos fundamentais de uma educação voltada para se trabalhar e viver em uma sociedade/economia do conhecimento. A conseqüência disso é que se os formuladores de políticas estivessem comprometidos a considerar a relação entre educação e economia do conhecimento, não deixariam de conferir ênfase às credenciais adquiridas por meio de baterias de testes e exames.

Por fim, seria bom enfatizar que embora tenham sido identificadas características distintivas da economia do conhecimento, é improvável que elas constituam um tipo diferente de capitalismo devido ao foco nos lucros e nos mercados (ver Brown, Lauder, 2006). Todavia, essa análise realmente não deixa de ter implicações para o papel da educação nesta nova fase de desenvolvimento capitalista.

\section{REFERÊNCIAS BIBLIOGRÁFICAS}

BECK, U. The risk society. London: Polity Press, 1992.

BELL, D. The coming of the post industrial society: a venture in social forecasting. New York: Basic Books, 1974.

Cultural contradictions of capitalism. New York: Basic Books, 1979

Foreward: the axial age of technology. In: BELL, D. The Coming of the post industrial society. Special anniversary ed. New York: Basic Books, 1999.

BRANDOM, R. Articulating reasons: an introduction to inferentialism. Cambridge: Harvard University Press, 2000.

BROWN, P.; LAUDER, H. Collective intelligence. In: BARON, S.; SCHULLER, T.; FIELD, J. (eds.). Social capital: critical perspectives. Oxford: Oxford University Press, 2003. p.224 Education for economic survival. London: Routledge, 1991.

BRUEGGER, U.; CETINA, K. K. Global microstructures: the interactional order of financial markets. Canadian Journal of Sociology, v.25, n.2, p. I 4I-168, 2000.

CALHOUN, C. Resisting globalization or shaping it? Prometheus, n. 4, p.29-47, 2000. Aspects of Enleghtenment. London: University College London Press.

CASTELLS, M. The Rise of the network society, the Information age: economy, society and culture, I. London: MacMillan, 1996. 
The Rise of the network society. 2.ed. London: MacMillan, 2000.

CETINA, K. Epistemic communities. Harvard: Harvard Education Press, 1999.

Sociality with objects: social relations in postsocial knowledge societies. Theory, Culture and Society, v. I 4, n.4, p. I-30, 1997.

- Transitions in post-social knowledge societies. In: BEN-RAFAEL, D.;

STERNBERG, E. (eds.). Identity, culture and globalization. Leiden, Boston, Koln: Brill, 200 I. p.713

DELANTY, G. Challanging knowledge. Buckingham: OU Press, 2001.

DENNETT, D. The Intentional stance. Cambridge: MIT Press, 1987.

DfEE. The Learning age. London: The Stationery Office, 1998.

DRUCKER, p.The Age of discontinuities. London: Transaction Publications, 1969.

EC. Lifelong learning memorandum. Brussels: EC, 200 I.

ERAUT, M. Informal learning in the workplace. Studies in continuing education, v.26, n.2, p.247-273, 2004.

ETZKOWITZ, H.; LEYDESDORFF, L. Universities in the global knowledge economy: a triple helix of academic-industry-government relations.London: Cassell, 1997.

GIBBONS, M. et al. New production of knowledge. London: Sage, 1994.

GUILE, D. Work experience in the European knowledge economy. Journal of Education and Work, n. I 5, v.3, p.25I-276, 2001 .

Knowledge and learning in the knowledge economy. Amsterdam: Sense, forthcoming. (no prelo)

Knowledge, reflection and higher education: a 'holy' yet problematic trinity?

forthcoming a. (no prelo)

LAUDER, H. et al. (eds.). Education, globalisation \& social change. Oxford: Oxford University Press, 2006.

LYOTARD, J-F. The postmodern condition: a report knowledge. Minnesota: University of Minnesota Press, 1988.

MOORE, R.; YOUNG, M. Knowledge and the curriculum: towards a reconceptualisation. British Journal of the Sociology of Education, v.22, n.4, p.445-46I, 2001.

MULLER, J. Reclaiming knowledge. London: Falmer, 2000. 
NELSON, R.; WINTER, S. In search of a useful theory of innovation. Research Policy, n.6, v. I, p.36-77, 1972.

NONAKA, I.; TAKEUCHI, H. The Knowledge creating company. New York: Oxford University Press, 1995.

NOWOTONY, H.; SCOTT, P.; GIBBONS, M. Re-Thinking science. London: Polity Press, 2001 .

OSBORNE, T. Aspects of enlightenment. London: University College London Press, 1998.

PENROSE, E. The Theory of growth of the firm. Oxford: Blackwell, 1959.

POLANYI, M. Personal knowledge: towards a post-critical philosophy. London: Routledge \& Kegan Paul, 1958.

The Tacit dimension.London: Routledge, Keegan and Paul, 1966.

PRAWAT, R. S. Cognitive theory at the crossroads: head fitting, head splitting, or somewhere in between? Human Development, v.42, n.2, p.59-77, 1999.

SCHILLER, D. The Information commodity: a preliminary view. In: DAVIS, J.; HIRSCHAL, T.; STACK, M. (eds.). Cutting edge, technology, information capitalisms and social revolution. London: Verso, 1997. p. I03-120.

SHAPIN, S. A Social history of truth: civility and science in Seventeenth Century England. Chicago: University of Chicago Press, 1994.

SPENDER, J-C. Competitive avantage from tcit knowledge: upacking the concept and its strategic implications. In: MOINGEON, B.; EDMONDSON, A. (eds.). Organizational learning and competitive advantage. London: Sage, 1996. p.326

STEHR, N. Knowledge societies. London: Sage, 1994.

THORPE, C. Science against Modernism: the relevance of the social theory of Michael Polanyi. British Journal of Sociology, n.52, v. I, p. 19-35, 1999.

WARD, S. Reconfiguring truth. Lanham, Maryland: Rowan and Littlefield Publishers, 1996.

WEBSTER, F. Information, urbanisms and identity: perspectives on the current work of Manuel Castells. City, n.7, p. 105-121, 1997.

ZUBOFF, S. In the age of the smart machine. London: Heinemann, 1988.

Recebido em: junho 2008

Aprovado para publicação em: julho 2008 